\title{
Comunicação
}

[Communication $]$

\section{Soropositividade para Mycoplasma hyopneumoniae em suínos abatidos em frigoríficos da região central do estado de São Paulo}

\author{
[Seropositivity for Mycoplasma hyopneumoniae in pigs at a Slaughterhouse \\ in the Central region of São Paulo] \\ A.F. Vicente, D. Catto, S.D. Allendorf, K.C.O.D. Garcia, J.M.A.P. Antunes, \\ C.M. Appolinario, M.G. Peres, J. Megid* \\ Faculdade de Medicina Veterinária e Zootecnia - Unesp - Botucatu, SP
}

A carne suína é a proteína animal mais consumida em todo o mundo, e o Brasil é o quarto maior produtor e exportador mundial (Abipecs, 2012). Atualmente é responsável por $10 \%$ do volume exportado de carne suína no mundo, chegando a faturar mais de US\$ 1 bilhão/ano (Brasil, 2012). Em 2010, o rebanho suíno brasileiro chegou a 38.956.758 milhões de cabeças, e só em janeiro de 2012 foram exportadas 37.756 toneladas de carne. Os principais destinos da carne suína brasileira são Hong Kong, Ucrânia, Argentina, Angola e Singapura, entretanto vários outros países restringem os produtos brasileiros em razão dos problemas sanitários nos rebanhos, ocasionados principalmente por doenças respiratórias e entéricas (Abipecs, 2012).

A pneumonia enzoótica suína (PES), causada pela bactéria Mycoplasma hyopneumoniae, é uma das principais doenças respiratórias dos suínos, não somente para a suinocultura brasileira como para a mundial (Conceição e Dellagostin, 2006; Maes et al., 2008; Pieters et al., 2009). Sua importância se deve à alta morbidade, em que o agente da PES causa redução da conversão alimentar, que diminui o ganho de peso médio diário. Em média, para cada $10 \%$ de pulmões lesionados, o ganho de peso médio diário é reduzido em 37 gramas. A PES é uma doença infecciosa crônica, contagiosa, caracterizada por uma broncopneumonia catarral (Conceição e

Recebido em 21 de março de 2012

Aceito em 5 de maio de 2013

*Autor para correspondência (corresponding author)

E-mail: jane@fmvz.unesp.br
Dellagostin, 2006) que se manifesta clinicamente por uma tosse não produtiva, observada entre 10 e 16 dias até seis a oito semanas após a infecção, variando com a cepa infectante (Maes et al., 2008; Pieters et al., 2009). Após esse período, os animais podem se tornar fontes de infecção, atuando como portadores assintomáticos capazes de infectar outros suínos susceptíveis (Pieters $e t$ al., 2009). A transmissão ocorre por contato direto, indireto e, principalmente, por meio de aerossóis eliminados durante os acessos de tosse. Afeta apenas a espécie suína, podendo atingir animais de todas as idades, porém a forma clínica da doença é mais comum nos animais em fase de crescimento e terminação (Conceição e Dellagostin, 2006; Maes et al., 2008).

Sitjar et al. (1996) sugerem que a soroconversão em infecções naturais leva cerca de 28 a 35 dias, mas, de acordo com Fano et al. (2005), dependendo do modo de infecção, a soroconversão pode ser mais tardia e lenta. O controle de infecções por $M$. hyopneumoniae pode ser realizado por otimização das práticas de gestão e condições das instalações ou por meio da utilização de antimicrobianos e vacinação (Maes et al., 2008). Em muitos países, a vacinação para controle da infecção por essa bactéria é aplicada em mais de $70 \%$ dos rebanhos suínos. Embora a vacina não impeça a colonização do agente no trato respiratório, ela reduz a multiplicação do agente e, consequentemente, diminui a taxa de infecção em um rebanho (Conceição e Dellagostin, 2006; 
Maes et al., 2008), levando a melhorias no ganho de peso diário (2-8\%) e na conversão alimentar (2-5\%) (Maes et al., 2008). Lesões sugestivas de PES foram relatadas por Malabarba et al. (2008) e Lopes et al. (2007).

Para a certificação das granjas de reprodutores suídeos, segundo instrução normativa $\mathrm{n}^{\circ} 19$, de 15 fevereiro de 2002, da defesa Agropecuária do Ministério da Agricultura, Pecuária e Abastecimento (Mapa), estas devem ser livres de peste suína clássica, doença de Aujeszky, brucelose, tuberculose, sarna, além de livre ou controlada para leptospirose. A critério do proprietário da granja de reprodutores, este poderá requerer junto ao Ministério da Agricultura, Pecuária e Abastecimento, a partir de junho de 2002, a certificação opcional de livre para outras doenças, entre as quais se destaca a certificação de livre para pneumonia enzoótica dos suínos (Brasil, 2009).

Estudos epidemiológicos são fundamentais para embasar programas de controle com ênfase na sanidade de suínos, portanto o objetivo deste trabalho foi avaliar a soropositividade para Mycoplasma hyopneumoniae em suínos pertencentes à região central do estado de São Paulo.

Segundo o Mapa, para fins de avaliação sorológica de granjas, recomenda-se uma amostragem de 59 animais para rebanhos com número superior a 5000 cabeças, tomando como base uma prevalência estimada de $5 \%$ e um nível de confiança de 95\% (Brasil, 2009). Adicionalmente, Rached (2009), no estado de São Paulo, relatou as pequenas criações de suínos e observou que $67 \%$ delas apresentaram, no máximo, 50 animais, incluindo os reprodutores e as matrizes, $17 \%$ possuem de 51 a 100 suínos, $10 \%$ de 101 a 200 e $6 \%$ possuem rebanho acima de 200 animais. Desta forma, foram analisadas 200 amostras de soro de suínos abatidos em frigoríficos da região central do estado de São Paulo (Tab. 1). Os animais apresentavam, em média, 140 dias de idade e eram procedentes de propriedades distribuídas por 14 cidades deste mesmo estado. As amostras de sangue, no total de 14 ou 15, correspondentes a cada município e oriundas de diferentes propriedades, foram coletadas, de forma aleatória, no momento do abate, durante o procedimento de sangria, e o soro obtido por centrifugação foi mantido a $-20^{\circ} \mathrm{C}$, até o momento do processamento. Nenhum dos animais analisados foi vacinado contra pneumonia enzoótica suína. Para a avaliação sorológica, adotou-se o método ELISA, utilizando-se o kit diagnóstico "IDEXX M. hyo. Ab Test" (Idexx Laboratories TM) de acordo com a metodologia preconizada pelo laboratório. Esse kit diagnóstico apresenta $98 \%$ de especificidade e 95\% de sensibilidade em situações de soro conversão pós-desafio (IDEXX, 2012).

Tabela 1. Municípios, número de amostras processadas e positivas, e percentual de positividade para $M$. hyopneumoniae

\begin{tabular}{cccc}
\hline Cidade & $\begin{array}{c}\mathrm{N}^{\mathbf{o}} \text { de amostras } \\
\text { processadas }\end{array}$ & $\mathrm{N}^{\mathrm{o}}$ de amostras positivas & $\begin{array}{c}\text { Positividade } \\
(\%)\end{array}$ \\
\hline Agudos & 14 & 4 & 28,5 \\
Areiopolis & 14 & 1 & 7,1 \\
Bariri & 15 & 3 & 20 \\
Bauru & 14 & 14 & 100 \\
Birigui & 14 & 10 & 71,4 \\
Botucatu & 15 & 2 & 13,3 \\
Fartura & 15 & 9 & 60 \\
Holambra & 14 & 13 & 92,8 \\
Itaberá & 14 & 11 & 78,5 \\
Itapetininga & 14 & 11 & 78,5 \\
Paranapanema & 14 & - & - \\
São Carlos & 15 & 12 & 80 \\
São Manoel & 14 & 3 & 21,4 \\
Tietê & 14 & 11 & 78,5 \\
\hline
\end{tabular}


Verificaram-se 52\% (104/200) de amostras positivas distribuídas em 13 das 14 cidades analisadas, o que sugere ampla disseminação do agente (Tab. 1 e Fig. 1). Esse percentual de soropositividade regional foi levemente inferior ao obtido por Carrijo (2012) em suínos procedentes de diversos municípios do estado de Santa Catarina diagnosticados com pneumonia enzoótica $(64,4 \%)$ pelo Serviço de Inspeção
Federal. Resultados similares foram obtidos por Silva et al. (2009), que detectaram $M$. hyopneumoniae em pulmões de suínos em crescimento e em terminação por meio da reação em cadeia pela polimerase (PCR), caracterizando a presença do agente nos pulmões de $52,6 \%$ das amostras analisadas de suínos que apresentavam alterações respiratórias.

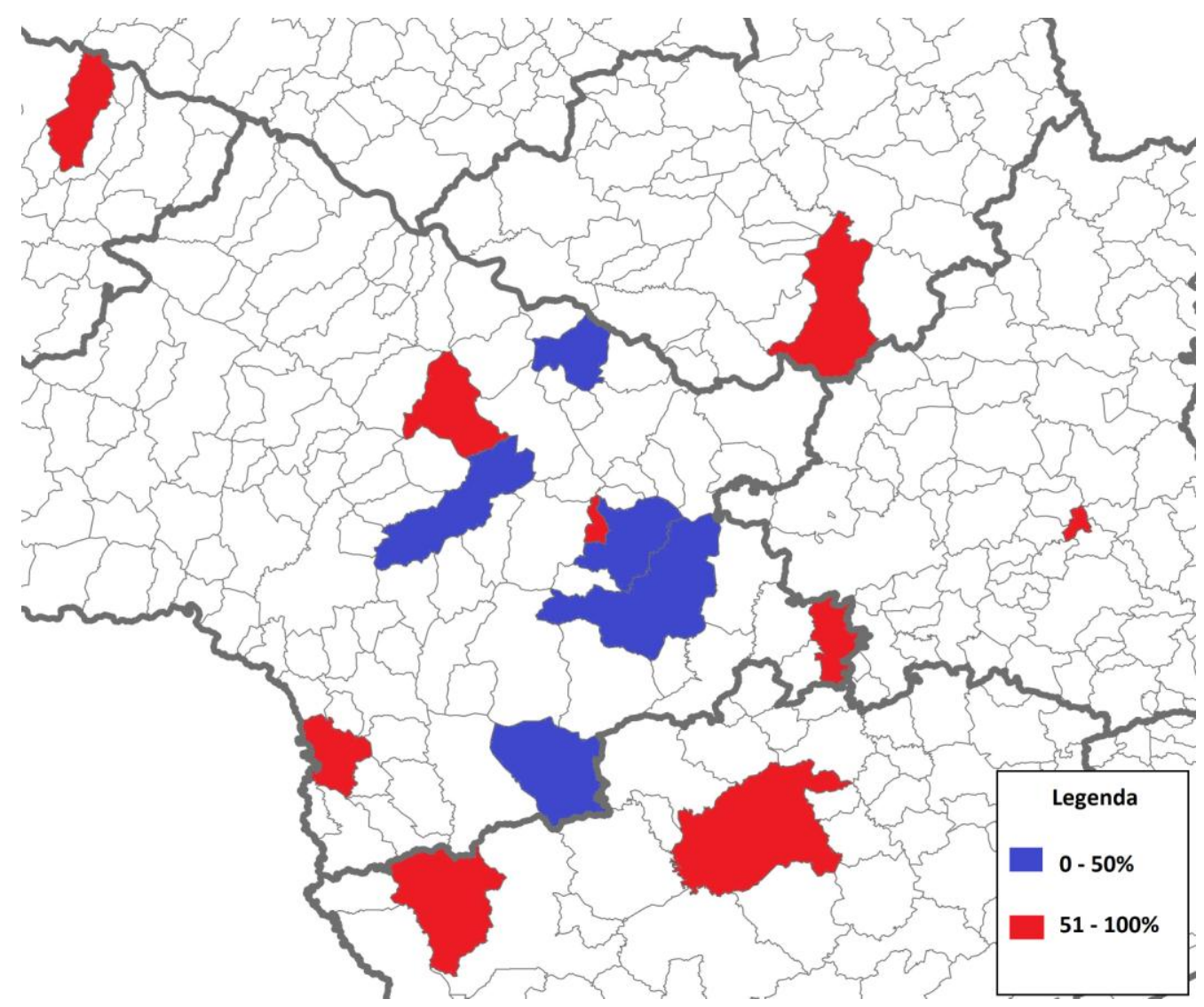

Figura 1. Porcentagem de soropositividade para Mycoplasma hyopneumonia em suínos abatidos em frigoríficos da região central do estado de São Paulo.

Kich e Pontes (2001) realizaram uma análise retrospectiva da situação das doenças respiratórias em suínos no Brasil e, com base na literatura consultada, relataram um aumento do percentual de suínos soropositivos para PES procedentes de rebanhos do sul do Brasil, São Paulo, Minas Gerais e Mato Grosso do Sul. Em 10 anos de estudo (1991-2001), houve um aumento de soropositivo para PES, em suínos abatidos, de $54,25 \%$ para $75,25 \%$. No estado de São Paulo, o percentual observado foi de $68,86 \%$ de animais com lesões de PES. Adicionalmente, estes autores relatam que levantamentos sorológicos, realizados pela Embrapa Suínos e Aves, utilizando-se a técnica de ELISA, demonstraram um aumento do percentual de animais soropositivos, em que as fases de crescimento e terminação apresentaram $86,15 \%$ de rebanhos com mais de $10 \%$ de animais soropositivos. Em relação aos resultados soronegativos na cidade de Paranapanema, Kich e Pontes (2001) ressaltam, também, a presença de rebanhos sorologicamente negativos e livres da infecção. 
De acordo com Maes et al. (2008), infecções por essa bactéria são altamente prevalentes em quase todas as áreas produtoras de suínos. Um fator que contribui para as altas porcentagens de positividade é o tempo de permanência da bactéria dentro do trato respiratório dos suínos. Pieters et al. (2009) demonstraram em seu estudo que os suínos eliminaram a bactéria até 214 dias após a infecção. Na presente pesquisa, os animais foram abatidos com, aproximadamente, 140 dias de idade. Sendo assim, todos os animais soropositivos talvez possam ter atuado como possíveis fontes de infecção até o dia de serem abatidos, independentemente de quando adquiriram a doença. A alta positividade do estudo pode ser justificada por possível transmissão vertical, pois, de acordo com Sibila et al. (2007), leitões sorologicamente positivos são procedentes, principalmente, de fêmeas positivas. Os autores consideraram esta forma de transmissão como um grande fator de risco para o desenvolvimento da doença no rebanho. Além disso, tal forma sugere o elevado percentual de positividade devido ao fato de os animais avaliados serem provenientes das fases de terminação e crescimento, quando a enfermidade é descrita mais prevalente (Kich e Pontes, 2001).

A elevada soropositividade sugere a circulação do Mycoplasma hyopneumoniae nos rebanhos suínos do centro-oeste paulista. A pneumonia enzoótica suína encontra-se disseminada, o que demonstra a necessidade do estabelecimento de programas de erradicação e controle dessa doença ou da introdução dela como doença de certificação livre obrigatória nos moldes das demais, dentro do Programa de Sanidade Suídea do Ministério da Agricultura, Pecuária e Abastecimento.

Palavras-chave: $M$. hyopneumoniae, epidemiologia, suínos

\begin{abstract}
Mycoplasma hyopneumoniae is the etiologic agent of enzootic pneumonia in pigs and causes large economic losses in the swine industry. There is little data on the positivity of this disease in Brazil. The objective of this study was to evaluate the seropositivity for this agent in 200 serum samples collected from pigs in a slaughterhouse located in the central region of São Paulo. A high percentage (52\%) of positivity was found indicating the presence of the agent and the need to implement control measures.
\end{abstract}

Keywords: M. hyopneumoniae, epidemiology, swine

\section{REFERÊNCIAS}

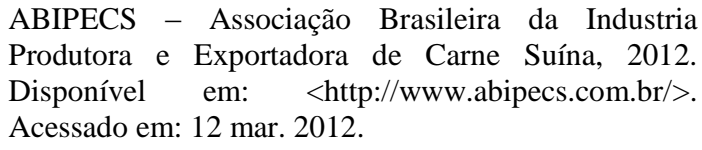

BRASIL - Ministério da Agricultura, Pecuária e Abastecimento, 2012. Suínos. Disponível em: $<$ http://www.agricultura.gov.br/animal/especies/suinos >. Acessado em: 12 mar. 2012.

BRASIL - Ministério da Agricultura, Pecuária e Abastecimento. Secretaria de Defesa Agropecuária. Departamento de Saúde Animal. Manual Técnico. Manual de Legislação. Programas Nacionais de Saúde Animal do Brasil, Brasilia, 2009. p.353-362.

CARRIJO, K.F. Diagnóstico de Mycoplasma hyopneumoniae e Circovírus suíno tipo 2 em tecidos pulmonar, renal e linfoide e de Leptospira spp. em suínos abatidos sob inspeção sanitária. 2012. 155 f. Tese (Doutorado em Higiene Veterinária e Processamento Tecnológico de Produtos de Origem Animal) - Universidade Federal Fluminense, Niterói.
CONCEIÇÃO, F.R.; DELLAGOSTIN, O.A. Etiopatogenia e imunoprofilaxia da pneumonia enzoótica suína. Cienc. Rural, v.36, p.1034-1042, 2006.

FANO, E.; PIJOAN, C.; DEE, S. Dynamics and persistence of Mycoplasma hyopneumoniae infection in pigs. The Canad. J. Vet. Res., v.69, p.223-228, 2005.

IDEXX Laboratories. IDEXX M. hyo. Ab Test . Controlling mycoplasmal pneumonia in swine: a continuous learning process. Disponível em: <http:// http://www.idexx.com.au/pdf/en_au/livestockpoultry/mhyo-ab-test-brochure.pdf $>$. Acessado em: 15 set. 2012.

KICH, J.D; PONTES, A.P. Análise da situação atual das doenças respiratórias no Brasil. Disponível em: $<$ http://www.cnpsa.embrapa.br/abravessc/pdf/Palestras2001/Jalusa_D_Kich.pdf >. Acessado em: 15 set. 2012. 
LOPES, P.C.S.; GRANDO, A.F.; KAMIMURA, R.; ARANTES, V.M. Prevalência e controle de pneumonia enzoótica no rebanho suíno de São Gabriel do Oeste de 2002 a 2004, 2007. Disponível em: <http://www.tecsa.com.br/ media/File/pdfs/POSTER\%20PNEUMONIA\%20ABR AVES\%202007.pdf >. Acessado em: 7 mar. 2012.

MAES, D.; SEGALES, J.; MEYNS, T. et al. Control of Mycoplasma hyopneumoniae infections in pigs. Vet. Microbiol., v.126, p.297-309, 2008.

MALABARBA, A.R.; DICKEL, L.E.; SANTOS, R.L.; FACENDA, G. Ocorrência de rinite atrófica e pneumonia enzoótica suína em um frigorífico da região norte do estado do Rio Grande do Sul. In: CONGRESSO BRASILEIRO DE MEDICINA VETERINÁRIA, 2008, Gramado. Anais... Gramado, 2008.

PIETERS, M.; PIJOAN, C.; FANO, E. et al. An assessment of the duration of Mycoplasma hyopneumoniae infection in an experimentally infected population of pigs. Vet. Microbiol., v.134, p.261-266, 2009
RACHED,R.Z. Caracterização de Pequenas Criações de Suínos no Estado de São Paulo. 2009. Dissertação (Mestrado em Sanidade, Segurança Alimentar e Ambiental no Agronegócio). Instituto Biológico de São Paulo, São Paulo, 2009.

SIBILA, M.; NOFRARIAS, M.; SORIA, S.L. et al. Exploratory field study on Mycoplasma hyopneumoniae infection in suckling pigs. Vet. Microbiol., v.121, p.352-356, 2007.

SILVA, F.M.F.; CASTRO, L.A.; SILVA JUNIOR, A. et al. Detection of Mycoplasma hyopneumoniae in lungs and nasal swabs of pigs by nested PCR. Arq. Bras. Med. Vet. Zootec., v.61, p.149-155, 2009.

SITJAR, M.; NOYES, E.; SIMON, X. et al. Relationships among seroconversion to Mycoplasma hyopneumoniae, lung lesions, and production parameters in pigs. Swine Health Prod, v.4, p.273-277, 1996. 